\title{
CERVICAL CANCER AWARENESS AMONG FEMALES OF REPRODUCTIVE AGE GROUP.
}

MBBS, MPH, MSc, MHPE. Associate Professor

Department of Community Medicine Coordinator Medical Education

Department

Rawal Institute Of health Sciences, Islamabad.

\section{Correspondence Address:}

Dr. Uzma Hassan

House No-24. Army Officers Housing Colony.

National Park Road. Rawalpindi. Pakistan.

dr.uzma.hassan@gmail.com

Article received on: 20/08/2018

Accepted for publication: 26/02/2019

Received after proof reading: $22 / 05 / 2019$

\begin{abstract}
Uzma Hassan
ABSTRACT... To evaluate cervical cancer awareness among females of reproductive age group. Study Design: Descriptive Cross-sectional study. Setting: Gynecology OPD of Rawal General and Dental Hospital, Islamabad. Period: Six months; March to September 2016. Materials and Methods: Total 200 females of reproductive age group (15-49 years) were included (patients and their attendants), by using the non-probability convenience sampling. A semi structured questionnaire was filled by interview method by the researcher. Questions were related to awareness of females regarding cervical cancer. The response was noted in 'Yes' and 'No' and they were calculated in percentages. Results: Married females (56\%), majority (45\%) belonged to $27-38$ years of age group, and maximum (46\%) had intermediate education. Response in 'Yes' was; Heard about cervical cancer (68\%), Heard about pap smear test (32\%), Had pap smear test (5\%), HPV is most common cause of cervical cancer (26\%), HPV can spread through direct sexual contact (40\%), Multiple sexual partners increase risk of cancer (64\%), Smoking increase risk of cancer (40\%), Vaccines available to prevent cervical cancer (38\%). Cervical cancer be prevented by following all measures (40\%), Never heard about Pap smear test (58\%). Majority did not know how often pap smear test be done (43\%). Both genders should have vaccine $(55 \%)$. By following all the measures awareness of cervical cancer can be increased (48\%). Conclusion: In this study awareness of cervical cancer along with its prevention was quite low in the women of reproductive age group. Insufficient knowledge of HPV infection was the reason of cervical cancer. The females were inadequately aware of the indications and significance of cervical cancer screening. Majority believed that Pap smear is performed only on the symptomatic women. The knowledge of women about the recipient of cervical cancer screening was poor.
\end{abstract}

Key words: $\quad$ Awareness, Cervical Cancer, Females of Reproductive Age Group, Pap Smear Test, Human Papilloma Virus.

Article Citation: Hassan U. Cervical cancer awareness among females of reproductive age group. Professional Med J 2019; 26(6):987-992.

DOI: $10.29309 / \mathrm{TPMJ} / 2019.26 .05 .3612$

\section{INTRODUCTION}

Cervical cancer is a kind of carcinoma which arises in the cells of the cervix, the lower part of the uterus that connects to the vagina. Numerous strains of the Human Papilloma Virus (HPV) a sexually transmitted infection plays an important role in causing most cervical cancer. ${ }^{1}$

Cervical carcinoma is considered as the second most communal cancer in females globally following cancer of breast in developing countries, however it is the most common cancer among women. ${ }^{2}$ According to $\mathrm{WHO}$, it was found that $80 \%$ of the 288,000 deaths out of 471,000 new cases globally were from the developing countries in $2000 .^{3}$

The foremost cause of cervical carcinoma in women is Human Papilloma Virus (HPV) and there is robust epidemiological proof associating cervical carcinoma to the Human Papilloma Virus (HPV) which is sexually transmitted. ${ }^{4}$

According to the studies about 35 kinds of HPV are identified which infect the genital tract among which nearly 20 are related with cervical carcinoma, and the commonest types are 16 and $18^{5}$. Multiple factors like early sexual debut, multiple sexual partners, smoking, Human Papilloma Virus infection, genetic predisposition 
and immunocompromised individuals are linked with cervical cancer development. ${ }^{6}$

The mortality and morbidity correlated to and associated with cervical carcinoma can decreased effectively by the help of screening and eliminating pre-invasive diseases. Various researches have depicted the sensitivity and specificity of Pap smear screening to be $50-75 \%$ and $98-99 \%$ respectively. ${ }^{7}$

Management for cervical carcinoma is conditional on the staging of the disease, medical status and age of the patient and tumor features. Options can be various like; monotherapy or combined, that ranges from simple hysterectomy with lymphadenopathy or simple hysterectomy without lymphadenopathy, radical hysterectomy with pelvic lymphadenopathy, chemotherapy, radiotherapy to palliative chemotherapy. Management at the very initial phase has the highest prognosis leading to cure rates at the maximum. ${ }^{8}$

The simplest and cost-effective procedure is the Pap smear test which aids in the early diagnosis of cervical carcinoma. It is vital to make the medical staff and nurses conscious and aware of cervical carcinoma which will help them to communicate information and understanding of the subject matter along with its preventive measures to the masses. It is considered as one of the only preventable carcinoma if discovered at its early stages.

This study will help to evaluate the awareness of cervical cancer among females of the reproductive age group. By assessing the level of awareness, evaluating the attitude and practice towards the disease it will serve as an instrument to find out the innovative measures to generate awareness among the females of reproductive age group. In our study the information about the causation of cervical cancer was also communicated to the females.

By assessing the awareness level and evaluating the results we can formulate practical recommendations which could benefit in preventing cervical cancer and to increase awareness about its risk factors among women.

The objective of the study was to evaluate the cervical cancer awareness among females of reproductive age group.

\section{METHODOLOGY}

Descriptive cross-sectional study conducted on 200 females of reproductive age group (15 - 49 years) visiting Gynecology OPD of Rawal General and Dental Hospital, during six months from March to September 2016. Study subjects were OPD patients and their attendants. The interview method was used by filling the structured close ended questionnaire by the researcher (myself) by selecting nonprobability convenience sampling. The study was approved by the ethical review committee of Institute. Proper consent was taken from the study subjects and the confidentiality was also assured. Pilot study was conducted on 20 respondents and changes were made in the questionnaire accordingly.

The questionnaire was divided into two portions. (Part A) included the biodata of females; marital status, age group and educational status. (Part B) was including questions related to awareness of females regarding cervical cancer. The response was noted in 'Yes' and 'No' for the following questions; Have you ever heard about cervical cancer, Heard about pap smear test, Ever had a pap smear test, HPV is most common cause of cervical cancer, HPV can spread through direct sexual contact, Multiple sexual partners increase risk of cancer, Smoking increase risk of cancer, There are vaccines to prevent cervical cancer, How cervical cancer can be prevented, What would be the reason for not having pap smear test, How often Pap smear test should be performed, Who should get the vaccine, How can awareness of cervical cancer be increased in females of reproductive age group. The responses were noted and calculated as percentages.

\section{RESULTS}

This study was conducted on total 200 females of reproductive age group (15-49 years) to evaluate their cervical cancer awareness. 
The Part $A$ of the questionnaire was related to biodata of the respondents; The marital status was; married (56\%), unmarried (42\%) and divorced (2\%). Age groups were categorized as; between 15- 26 years (23\%), 27- 38 years (45\%), $39-50$ years $(32 \%)$. The educational status was grouped as; illiterate $(6 \%)$, Matric $(34 \%)$, Intermediate (46\%) and Bachelors/Masters (14\%).

The Part B of the questionnaire was related to the questions concerning the awareness of females regarding cervical cancer Table-I. The questions were asked about the different variables related to the awareness of cervical cancer. The response noted in 'Yes' was calculated in percentages for the following questions; Have you ever heard about cervical cancer (68\%), have you ever heard about pap smear test (32\%), In this study though the females knew about the cervical cancer, they lacked the urge to take the test, have you ever had a pap smear test (5\%), do you think HPV is the most common cause of cervical cancer (26\%), do you think HPV can spread through direct sexual contact (40\%), do you think multiple sexual partners increases the risk of cervical cancer (64\%), do you think smoking can increase the risk of cervical cancer (40\%), do you think there are vaccines available to prevent cervical cancer (38\%).

Other questions asked were related to the variables as follows; As shown in Table-Il how cervical cancer be prevented; (40\%) by following all the options like measures like regular screening, through HPV vaccination, use of condoms, avoid multiple sexual partners, quit smoking. In Table-III If you never had a pap smear test what was the reason for it; (56\%) never heard about it. In Table-IV How often do you think Pap smear test should be done; majority (43\%) did not know about it. In Table-V who do you think who should get the vaccine; (55\%) said both genders. In the Table-VI how can awareness of cervical cancer be increased in women of reproductive age group; (48\%) said to follow all the options like educating females about cervical cancer screening, by promoting advertisements through TV, newspaper, radio, by launching public awareness campaign, through vaccination program. The responses were noted and calculated as percentages.

\begin{tabular}{|c|l|c|c|c|c|}
\hline \multicolumn{1}{|c|}{ Variables } & \multicolumn{3}{|c|}{ Response } \\
\hline S/No & \multicolumn{1}{|c|}{ Questions Asked } & Yes & $\%$ & No & $\%$ \\
\hline 1. & Have you ever heard about cervical cancer & 136 & $68 \%$ & 64 & $32 \%$ \\
\hline 2. & Have you ever heard about pap smear test & 64 & $32 \%$ & 136 & $68 \%$ \\
\hline 3. & Have you ever had a pap smear test & 10 & $5 \%$ & 190 & $95 \%$ \\
\hline 4. & $\begin{array}{l}\text { Do you think Human Papilloma Virus (HPV) is the most common cause } \\
\text { of cervical cancer }\end{array}$ & 52 & $26 \%$ & 148 & $74 \%$ \\
\hline 5. & Do you think HPV can spread through direct sexual contact & 80 & $40 \%$ & 120 & $60 \%$ \\
\hline 6. & $\begin{array}{l}\text { Do you think multiple sexual partners increases the risk of cervical } \\
\text { cancer }\end{array}$ & 128 & $64 \%$ & 72 & $36 \%$ \\
\hline 7. & Do you think smoking can increase the risk of cervical cancer & 80 & $40 \%$ & 120 & $60 \%$ \\
\hline 8. & Do you think there are vaccines available to prevent cervical cancer & 76 & $38 \%$ & 124 & $62 \%$ \\
\hline
\end{tabular}

Table-I. Different parameters of awareness of cervical cancer among females of Reproductive age group. $(n=200)$

\begin{tabular}{|c|l|c|c|}
\hline S/No & \multicolumn{1}{|c|}{ How cervical cancer can be prevented } & Number & $\%$ \\
\hline a. & By regular screening & 12 & $6 \%$ \\
\hline b. & Through HPV vaccination & 64 & $32 \%$ \\
\hline c. & Use of condoms & 12 & $6 \%$ \\
\hline d. & Avoid multiple sexual partners & 16 & $8 \%$ \\
\hline e. & Quit smoking & 16 & $8 \%$ \\
\hline f. & All the above & 80 & $40 \%$ \\
\hline
\end{tabular}

Table-II. How cervical cancer can be prevented $(n=200)$ 


\begin{tabular}{|c|l|c|c|}
\hline S/No & \multicolumn{1}{|c|}{ If you never had a pap smear test, what was the reason for it } & Number & $\%$ \\
\hline a. & Never heard about it & 112 & $56 \%$ \\
\hline b. & No one recommended & 76 & $38 \%$ \\
\hline c. & Fear of embarrassment & 4 & $2 \%$ \\
\hline d. & Family/ religious reasons & 4 & $2 \%$ \\
\hline e. & Painful procedure & 4 & $2 \%$ \\
\hline
\end{tabular}

Table-III. Reason for not having pap smear test $(n=200)$

\begin{tabular}{|c|l|c|c|}
\hline S/No & \multicolumn{1}{|c|}{ How often do you think Pap smear test should be done } & Number & $\%$ \\
\hline a. & Once a year & 68 & $34 \%$ \\
\hline b. & Every three years & 26 & $13 \%$ \\
\hline c. & Every five years & 20 & $10 \%$ \\
\hline d. & Do not know & 86 & $43 \%$ \\
\hline
\end{tabular}

Table-IV. How often should Pap smear test be done $(n=200)$

\begin{tabular}{|c|l|c|c|c|}
\hline S/No & \multicolumn{2}{|c|}{ Who do you think should get the vaccine } & Number & $\%$ \\
\hline a. & Young boys & 4 & $2 \%$ \\
\hline b. & Young girls & 84 & $42 \%$ \\
\hline c. & Both & 110 & $55 \%$ \\
\hline d. & None & 2 & $1 \%$ \\
\hline
\end{tabular}

Table-V. Who should get the vaccine $(n=200)$

\begin{tabular}{|c|l|c|c|}
\hline S/No & \multicolumn{1}{|c|}{ How can awareness of cervical cancer be increased } & Number & $\%$ \\
\hline a. & By educating females about cervical cancer screening & 36 & $18 \%$ \\
\hline b. & By promoting advertisements through tv, newspaper, radio & 24 & $12 \%$ \\
\hline c. & By launching a public awareness campaign & 24 & $12 \%$ \\
\hline d. & Through vaccination program & 20 & $10 \%$ \\
\hline e. & All of the above & 96 & $48 \%$ \\
\hline
\end{tabular}

Table-VI. How can awareness of cervical cancer increased $(n=200)$

\section{DISCUSSION}

Cervical cancer is the female genital tract cancer that arises due to the dysplasia of the cells lining the cervix. The most communal causes of cervical cancer are Human Papilloma Virus, multiple sexual partners and intercourse in the young age. It can transmit through direct sexual skin to skin contact. Cervix the lower end of the uterus opens into the vagina which has two parts the exo cervix and the endo cervix. The exo cervix is lined by squamous epithelium and the endo cervix is lined by glandular cells. The place where these two type of cell meet is known as the transformation zone which is the commonest site of the cervical cancer. The lesion in this area first causes precancerous changes, which if not treated can lead to lethal cancerous disorders and conditions.

Globally in women Cervical carcinoma is the second most communal cancer. Unlike many carcinomas the prevention of cervical carcinoma can be facilitated by adopting the preventive methods from infection by Human Papilloma Virus or by following the measures of early detection and management of the precancerous lesions before they transform to invasive carcinoma.

Carcinoma of cervix is a worldwide crisis and leading cause of mortality and morbidity globally. It is the second most communal gynecological carcinoma worldwide in females and overall seventh most communal cancer, with about 528,000 fresh cases diagnosed in 2012. In the coming 20 years it is estimated that the incidence and mortality are expected to increase. In the year 2012, it was calculated total 266,000 deaths from cervical cancer globally, compared to $7.5 \%$ of all cancer deaths in women.

The mortality rate of cervical carcinoma was superior in under developed countries due to 
lack of screening for precancerous lesions and management that could cure them or prolong their life expectancy while the number of deaths was very less in developed region like Australia, New Zealand, and Western Europe; the main reason is the provision of national screening programs and vaccine against Human Papilloma Virus.

Pakistan has a rising tendency of cervical cancer cases due to dearth of awareness, which are usually detected at later stage when a woman is in the crucial stage of life supervising and looking after her family.

According to the Global Crisis Card Pakistan has been ranked the seventh amongst countries with maximum mortality due to cervical cancer. In a research done by $\mathrm{WHO}$ it has been highlighted that the incidence of cervical cancer in Pakistan has increased. It concluded that Pakistan is shifting from the level of low risk to moderate risk transforming it as a dangerous zone where the young girls are now considered as high risk.

Unfortunately, In Pakistan screening for Human Papilloma Virus infection is not a usual practice and tradition. Sporadic screening is being conducted out in certain clinics and hospitals due to dearth of awareness.

In a recent study in Pakistan stated that the awareness and understanding of availability of cervical carcinoma screening in the general population was only $5 \%$ and for the sample only $2.6 \%$ had ever undergone a Pap smear test. If we talk about screening the frequency is lesser in Pakistan in comparison to other countries. According to the guidelines in Pakistan it is recommend that Pap smear is to be done after every three years as compared to guidelines of American Cancer Society which recommends screening to be once a year.

\section{CONCLUSION}

It was found that the awareness of cervical cancer along with its prevention was quite low in the women of reproductive age group. The study results depict insufficient knowledge of HPV infection being the reason of cervical cancer.
The females were inadequately aware of the indications and significance of cervical cancer screening. Majority believed that Pap smear is performed only on the symptomatic women. The knowledge of women about the recipient of cervical cancer screening was poor.

\section{RECOMMENDATIONS}

Public awareness programs should be carried out at Government level regarding Cervical Cancer and also projected to general population through electronic media. Female awareness campaign should be conducted at clinical level and should also be enhanced at mass level with collaboration of Gynecologist and Obstetricians, who should educate and convince every female patient to come to their clinic. Booklets relating to the general information of cervical cancer should be dispersed and distributed at every medical center level like; $\mathrm{BHU}, \mathrm{RHC}, \mathrm{THQ}$, and $\mathrm{DHQ}$. The HPV vaccination should be readily available and encouraged to be taken by respective young individuals and couples.

Cervical carcinoma is the only avoidable cancer if diagnosed at the initial stages. Pap smear test is considered as a cost-effective and simple procedure for early detection. It is obligatory to make the medical staff and nurses aware of cervical carcinoma so that they are able to communicate the understanding related to subject matter and its prevention to the masses. An essential secondary preventive technique for cervical carcinoma is Population based screening with Pap smear that aids to maximum cure rates in the patients suffering from cervical carcinoma. ${ }^{9-12}$

Further research should be carried out mainly targeting the incidence of cervical cancer in patients in relation with the risk factors that causes it.

\section{Copyright@ 26 Feb, 2019.}

\section{REFERENCES}

1. Laikangbam P, Sengupta S, Bhattacharya P, Duttagupta C, DHABALI SINGH T, Verma $Y$, et al. A comparative profile of the prevalence and age distribution of human papillomavirus type 16/18 infections among three states of India with focus on northeast India. International Journal of Gynecological Cancer. 2007; 17(1):107-117. 
2. Organization $W H$. International agency for research on cancer. Attributable causes of cancer in France in the year 2000. 2000; 60-64.

3. Bharadwaj M, Hussain S, Nasare V, Das BC. HPV \& HPV vaccination: Issues in developing countries. Indian $\mathrm{J}$ Med Res. 2009 Sep; 130(3):327-33.

4. Shaping a strategy to introduce HPV vaccines in India. Formative research results from the HPV vaccines: Evidence for Impact project [Internet]. PATH and National AIDS Research Institute; 2009 p. 25. Available from: http://www.path.org/

5. Mattheij I, Pollock AM, Brhlikova P. Do cervical cancer data justify HPV vaccination in India? Epidemiological data sources and comprehensiveness. Journal of the Royal Society of Medicine. 2012; 105(6):250-262.

6. Bingham A, Drake JK, LaMontagne DS. Sociocultural issues in the introduction of human papillomavirus vaccine in low-resource settings. Archives of pediatrics \& adolescent medicine. 2009; 163(5):455461.

7. Nganwai $P$, Truadpon $P$, Inpa C, Sangpetngam B, Mekjarasnapa M, Apirakarn M, et al. Knowledge, attitudes and practices vis-a-vis cervical cancer among registered nurses at the Faculty of Medicine, Khon Kaen University, Thailand. Asian Pac J Cancer Prev. 2008; 9(1):15-8.
8. Anya SE, Oshi DC, Nwosu SO, Anya AE. Knowledge, attitude, and practice of female health professionals regarding cervical cancer and Pap smear. Nigerian Journal of Medicine: Journal of the National Association of Resident Doctors of Nigeria. 2005; 14(3):283-286.

9. Ali SF, Ayub S, Manzoor NF, Azim S, Afif M, Akhtar N, et al. Knowledge and awareness about cervical cancer and its prevention amongst interns and nursing staff in Tertiary Care Hospitals in Karachi, Pakistan. PloS one. 2010; 5(6):e11059.

10. Mutyaba T, Mmiro FA, Weiderpass E. Knowledge, attitudes and practices on cervical cancer screening among the medical workers of Mulago Hospital, Uganda. BMC medical education. 2006; 6(1):13.

11. Udigwe GO. Knowledge, attitude and practice of cervical cancer screening (Pap smear) among female nurses in Nnewi, South Eastern Nigeria. Nigerian journal of clinical practice. 2006; 9(1):40-43.

12. McCarey C, Pirek D, Tebeu PM, Boulvain M, Doh AS, Petignat P. Awareness of HPV and cervical cancer prevention among Cameroonian healthcare workers. BMC women's health. 2011; 11(1):45.

\begin{tabular}{|l|l|l|l|}
\hline \multicolumn{3}{|c|}{ AUTHORSHIP AND CONTRIBUTION DECLARATION } \\
\hline Sr. \# & Author-s Full Name & Contribution to the paper & Author=s Signature \\
\hline 1 & Uzma Hassan & Corresponding Author & \\
\hline
\end{tabular}

